\title{
PATRONES DE LA FECUNDIDAD EN BOLIVIA
}

\section{Lilian Delgado Gonzáles y Pamela Córdova Olivera}

\section{RESUMEN}

La fecundidad es uno de los componentes importantes de la transición demográfica, el cual determina la estructura y crecimiento de una población específica. Bolivia, al igual que el resto de los países latinoamericanos, presenta un descenso de esta tasa, primordialmente explicado por factores no convencionales como la globalización, que influyen en el comportamiento de los cambios económicos, sociales y en temas relativos al empoderamiento de la mujer. El cambio en las características socioeconómicas destaca la heterogeneidad de la población boliviana, influenciando en los niveles de urbanización y permitiendo mejoras en los sectores de educación y salud. No obstante, regiones menos desarrolladas preservan comportamientos tradicionales que influyen significativamente en el nivel de fecundidad. Por lo tanto, el presente trabajo tiene como objeto investigar y analizar los principales determinantes que influyen en el nivel de fecundidad del país con el fin de comprender su comportamiento. Para este análisis, se considera los tres niveles de impacto: Determinantes socioeconómicos individuales y de exposición, a nivel del hogar y contextuales, la cual a través de una estimación empírica permitirá analizar los efectos de los factores que influyen en la probabilidad de ocurrencia del evento (modelo PROBIT); es decir, qué influye en la decisión de tener o no hijos (indistintamente del número). Para ello, la información utilizada parte de la Encuesta de Demografía y Salud (ENDSA) para la gestión 2008, que consiste en una muestra probabilística de 16.925 mujeres entre 15 a 49 años; por lo cual permite rescatar la información de su historial completo de fecundidad.

Palabras clave: Fecundidad, Transición demográfica, Modelo Probit.

DOI: $10.23881 /$ idupbo.017.2-5e 